\title{
38 Countries Can't All Be Wrong
}

When I was asked to write an editorial for the journal, my first reaction was "What do I have to say that needs to be in the form of an editorial?" Fortunately, I was preparing to attend the $16^{\text {th }}$ International Congress of Dento Maxillo Facial Radiology in Beijing, where I was to present an invited paper on The Status of Oral and Maxillofacial Radiology Worldwide in 2007.

I have been interested in this topic for over thirty years, when I, as a third year resident in Oral Radiology at the University of Toronto, was asked by the president of the American Academy of Dental Radiology, Professor Coleman Reed Tuckson, to look into the status of Dental Radiology in Canada. As a direct result of my gathering the information the organization now called The Canadian Academy of Oral and Maxillofacial Radiology was founded. I was made chair of the specialty committee, and on behalf of the academy applied to the Canadian Dental Association for specialty recognition for Oral Radiology. This was granted in 1973. At that time Oral and Maxillofacial Radiology was recognized in India, and maybe two or three other countries, where the record of which year recognition was granted has been lost.

In 1999, I was co-chair of the specialty committee of the American Academy of Oral and Maxillofacial Radiology which, after four applications, received specialty recognition from the American Dental Association. By that time the total number of countries recognizing Oral and Maxillofacial Radiology had climbed to at least 15.

And this trend has continued. Today Oral and Maxillofacial Radiology, by whatever name it is known, is recognized in one form or other in at least 38 countries, from most of the Americas through North Europe, and via large parts of Africa, the Middle East and Asia to Australia. And there are applications pending in four additional countries.

The reason for this is obvious to anyone who is deeply involved in radiology. Dentistry has evolved from a profession that concentrated only on restoration and extraction of the teeth, to a profession that sees its responsibility extending, by way of the entire maxillofacial region, to diseases and treatment in much of the head and neck, a profession whose treatment ranges from prevention of dental diseases through placement of implants as a more sophisticated way to treat tooth loss, to one that sees its relationship to the whole pa- tient. With this comes the responsibility for being able to adequately investigate and diagnose the health status in a wider anatomical area. The explosion in radiographic imaging modalities and techniques, the linkage of private practitioners to specialists via the web, and the expectation of having a specialist who is capable of interpreting images of this wider area, has revolutionized how dentists practice. Nowhere is this growth in responsibility more obvious than in oral and maxillofacial radiology itself.

It is no longer to be expected that dental general practitioners or specialists outside of radiology can or should be experts in all aspects of Oral and Maxillofacial Radiology. If we are to provide the best care to our patients we must ensure that the dental profession has the needed specialized practitioners with whom to collaborate. Practitioners who are dentists, and understand dental diseases, dental treatment, and abnormalities in our area within the context of dental care. Someone to whom the general practitioner or specialist can turn for specialized knowledge in order to decide upon the appropriate treatment for our patients. Someone with whom to consult. A dentist's dentist. Or, to paraphrase Abraham Lincoln, a famous American President, a dentist of the profession, by the profession and for the profession.

This is not unreasonable. Dentistry was an early user of radiographs. It was often the dental practitioner who had the x-ray unit in small towns, and therefore had physicians refer patients for investigation of all manner of disease. It is time for dentistry to once again accept its rightful place as a health care profession that places the welfare of its patients first, by ensuring that it continues to grow and evolve. It can do so only if it allows all areas of its profession to grow and develop, to ensure that it has specialists in these various knowledge-based areas who can relate to the needs of dentists and assist them in providing the most appropriate care for their patients in a timely manner.

I believe that recognition of Oral and Maxillofacial Radiology as a dental specialty whose time has truly come is long overdue. Our profession deserves it. Our patients deserve it.

Thirty-eight countries agree.

Ruprecht, A. The Status of Oral and Maxillofacial Radiology Worldwide in 2007. The 16th International Congress of Dento Maxillo Facial Radiology, Beijing, China, June 26, 2007. 